\title{
La violación sexual es política: las migrantes venezolanas en las fronteras colombo-venezolanas ${ }^{1}$
}

\section{Rape is politics: Venezuelan migrants on the Colombian-Venezuelan borders}

\section{Liliana Mancilla Bautista iD}

Corporación Unificada Nacional de Educación Superior CUN, Colombia

liliana_mancilla@cun.edu.co

\section{Resumen}

El presente artículo tiene como objetivo aproximarse a analizar la violación sexual que han experimentado las mujeres migrantes venezolanas en las zonas de frontera entre Colombia y Venezuela durante la más reciente etapa de éxodo venezolano. Para esto, se partirá de la reflexión sobre los aportes teóricos de Rita Laura Segato acerca de las nuevas expresiones de la violencia contra la mujer y cómo el consumo del cuerpo femenino y el odio hacia el cuerpo de la mujer extranjera hacen parte de la construcción de un sistema de poder patriarcal paraestatal, donde la violación tiene que ver más con una expresión del poder politico — por medio de un cuerpo-territorio-que con el deseo sexual, a pesar de sexualizar el cuerpo a través de su profanación. Esta indagación se hará a partir del diálogo de los aportes de Segato y otras autoras que circundan el tema de las relaciones de dominación y apropiación de la mujer, y se tomarán de fuentes secundarias diversos relatos de las migrantes para comprender este fenómeno. Por último, se señalarán los límites teóricos de la propuesta de Segato relacionados con la producción de un sujeto mujer-víctima-sacrificial sin capacidad de agencia, ni de reapropiación de su cuerpo como campo político para vindicar la reparación y desafiar al mandato masculino.

Palabras clave: estatus migratorio irregular, frontera colombo-venezolana, mandato masculino paraestatal, mujeres venezolanas migrantes, poder politico, violación sexual.

\begin{abstract}
The general objective of this article is to investigate the rape that Venezuelan migrant women have experienced in the border areas between Colombia and Venezuela in the most recent stage of the Venezuelan exodus, this exploration will be developed from reflecting on the theoretical contributions of Rita Laura Segato about the new expressions of violence against women and how the consumption of the female body, hatred towards the foreign woman's body are part of the construction of a parastatal patriarchal power system, where rape has to do more with an expression of political power, through a body-territory, than with sexual desire, despite the fact that the body is sexualized through its desecration. This inquiry will be made from the dialogue of the contributions of Segato and other authors that surround the subject of relations of domination and appropriation of women, and some stories of migrants will be taken from secondary sources to understand this phenomenon. Finally, the theoretical limits of Segato's proposal related to the production of a womanvictim subject without agency capacity, nor of reappropriation of her body as a political field to vindicate reparation and challenge the masculine mandate, will be pointed out.
\end{abstract}

Keywords: Colombian-Venezuelan border, irregular inmigration status, venezuelan migrant women, parastatal malemandate, political power, rape.

Articulo: Recibido el 10 de septiembre de 2021 y aprobado el 1 de noviembre de 2021

\section{Cómo citar este artículo:}

Mancilla Bautista, L. (2021). La violación sexual es política: las migrantes venezolanas en las fronteras colombovenezolanas. Reflexión política 23(48), pp. 26-38. doi: https://doi.org/10.29375/01240781.4237

1. Este artículo es producto del desarrollo del proyecto de investigación "La movilidad humana de Venezuela hacia Colombia: las zonas de frontera y Bogotá como espacios para la integración económica y política de la población migrante en el periodo de 2017-2020", aprobado bajo el código institucional INV-NEG-BOG-G404-PROY2021-09 en febrero de 2021. 


\section{Introducción}

La frontera entre Colombia y Venezuela tiene una extensión de aproximadamente 2.200 kilómetros; sin embargo, los pasos clandestinos para los migrantes irregulares que cruzan desde el vecino país hacia Colombia por el departamento de Norte de Santander se han convertido en el territorio para la violencia sexual sobre las migrantes que atraviesan estas rutas. A causa de la presencia paraestatal de grupos armados al margen de la ley que controlan las zonas fronterizas, las violaciones sexuales sobre estas mujeres se han convertido en uno de los fenómenos más recurrentes, pero invisibilizados, en la más reciente etapa de éxodo venezolano. En ese sentido, el presente artículo expone dos aproximaciones teóricas acerca de las violaciones sexuales ejercidas sobre las migrantes en las zonas de frontera binacional; por un lado, se indaga por el carácter sexual de estas violaciones, y en un segundo momento se presenta una reflexión a la luz de los aportes teóricos de Rita Laura Segato para dar cuenta del carácter político de la violación sexual sobre las migrantes.

El contexto que enmarca este fenómeno está relacionado con la más reciente etapa de migración venezolana (2015 - 2018) cuyo destino especialmente han sido países de la región suramericana. Este flujo migratorio está caracterizado por las condiciones sociales que han producido el éxodo desde Venezuela; entre algunos aspectos se encuentran: el detrimento en las necesidades básicas de vida de los habitantes de Venezuela; la escasez de alimentos, medicamentos e insumos; el desempleo; el aumento hiperbólico de la inflación y la tasa de pobreza; y el descenso del PIB. La convergencia de estas condiciones ha generado una profunda crisis en la población de menores condiciones socioeconómicas y ha empujado a una porción considerable de sus ciudadanos al despojo de su hábitat (aproximadamente el 8\% del total de la población). Esta crisis humanitaria, declarada en 2019 por la Human Rights Watch como una "emergencia humanitaria compleja" (párr.7), ha marcado profundamente la calidad de vida de las comunidades residentes en Venezuela, pero también se ha convertido en la causa primordial del éxodo, cuyo principal destino ha sido Colombia.

A corte de octubre 31 de 2020, aproximadamente el 55\% del flujo migratorio de Venezuela hacia Colombia ha sido irregular (Migración Colombia, 2020), con tal suerte que el ingreso al territorio colombiano se ha realizado por un paso fronterizo fuera de los controles migratorios estatales y de la vigilancia fronteriza; durante su tránsito o radicación en Colombia la situación jurídica es de un estatus migratorio irregular, es decir, no ha sido autorizado su movimiento migrante por las autoridades colombianas. Esta condición de irregularidad o el carácter ilícito es procedente del control estatal (Álvarez, 2021).

En este sentido, los tránsitos migratorios de carácter irregular o clandestino constituyen gran parte del contexto que generala desprotección a esta población, pues durante su trayecto migratorio y la radicación de esta comunidad en Colombia, experimenta vulnerabilidad y marginación, ya

que los migrantes venezolanos están sometidos a diversas expresiones de violencia durante su ruta. Particularmente en este proceso de migración se ha puesto en evidencia que dentro del grupo de migrantes algunos de sus miembros, debido a su estatus migratorio, género, clase social, estatus y rol social, y etnia, han padecido violencias particulares.

Siguiendo esta línea, es importante mencionar que el 49\% de los flujos migratorios -en los últimos cinco años- está representado por mujeres (Migración Colombia, 2020). Ellas, en su proceso de movilidad humana en las zonas de frontera colombo-venezolana, han sufrido casos de violencia sexual y violencia sexualizada (Centro de Justicia y Paz, 2019; Fundación PARES, 2021). Este artículo indaga sobre la violación sexual ejercida sobre las migrantes. Desde este contexto, el cuerpo de la mujer ha sido cosificado y su corporalidad ha representado el lugar donde se expresan los actos de violencia y rapiña. La misma consumición del cuerpo expresan la más exacta cosificación de la vida (Segato R. , 2018).

De esta forma, una gran cantidad de sucesos han sido observados y difundidos tanto por algunos medios de comunicación, como por ONG’s que se han encargado de visibilizar las violaciones sexuales a las migrantes en la frontera binacional en el municipio de Cúcuta (Colombia) desde el año 2015 (Universo 
Centro, 2020; Fundación Paz y Reconciliación, 2021). Segato (2018) denomina a las desapariciones, la tortura, violencia física, violencia sexual y al homicidio contra las mujeres en Ciudad Juárez como "epifenómenos", pues esta violencia ejercida de manera pública sobre las mujeres en zona de frontera (entre México y Estados Unidos) es efecto de las decisiones del poder (Segato R. , 2018, pág. 68). En consecuencia, se retoman los aportes de Segato (2018) para indagar sobre las violaciones sexuales cometidas sobre las migrantes venezolanas en los territorios limítrofes entre Colombia y Venezuela, en el sentido en que Segato en obras como Las nuevas formas de la guerra y el cuerpo de las mujeres (2013) ha problematizado sobre el nuevo rol de la mujer - no como sujeto sino como objeto de guerra- en la cual su cuerpo es el instrumento para escribir el mensaje político de control sobre la vida y el territorio; esta consigna es trazada de manera violenta. También en trabajos como El sexo y la norma: frente estatal, patriarcado, desposesión, colonialidad (2014) la autora señala la desposesión del cuerpo propio de la mujer ${ }^{2}$ y la apropiación de este a manos de la estructura patriarcal como un proceso histórico colonial. Así mismo, de manera más precisa en obras como La guerra contra las mujeres (2016) y Contrapedagogías de la crueldad (2018) aborda el fenómeno de la violencia contra la mujer en la frontera entre México y Estados Unidos.

Así, a pesar de ser unidades de estudio distintas espacial y temporalmente las categorías conceptuales y teóricas sobre la presencia y el control paraestatal en los territorios fronterizos, la forma en la que el mandato masculino mafioso del Segundo Estado ${ }^{3}$ pacta ejercer control sobre la vida de las poblaciones y le asigna al cuerpo de la mujer un nuevo rol para que a través de la profanación sexual se exprese un mensaje político, estos ejercicios de poder opresivo están presentes tanto en las fronteras mexicanas como en las colombovenezolanas . La unidad de análisis de los crímenes públicos de género (Segato R. L., 2013; 2014; 2018), se convierte en una herramienta teórica y conceptual potente para indagar varios casos de violencia sexual contra las mujeres migrantes que ingresan por los pasos irregulares hacia Colombia, las denominadas "trochas", entendidos como los pasos irregulares o ilegales en las fronteras colombovenezolanas, los cuales han sido construidos de forma alternativa para el tránsito ilícito migrante por fuera de la autoridad y vigilancia migratoria estatal; estas trochas son custodiadas por las estructuras del Segundo Estado.

Estos episodios de violación sexual en la frontera colombo-venezolana han sido atribuidos a diversos actores presentes en esos territorios; por una parte, los traficantes de personas y la presencia y control de las "trochas" por parte de grupos ilegales transnacionales que controlan las áreas binacionales de “... Cúcuta, Villa del Rosario, Puerto Santander, Zulia, Táchira y Apure, los Rastrojos... los Evander trabajan de la mano con los Rastrojos" (Fundación Paz y Reconciliación, 2019, pág. 23), además de la presencia del Ejército de Liberación Nacional (ELN), Ejército de Liberación Popular (EPL), "Los Pelusos", han perpetrado hechos de violencia sexual contra las mujeres migrantes (Fundación Paz y Reconciliación, 2020, pág .96) . También se han reportado casos de desapariciones forzadas de mujeres migrantes (Universo Centro, 2020).

Es importante mencionar que el cierre de la frontera en 2015 durante diez meses (Observatorio de Venezuela Universidad del Rosario, 2019) generó la apertura de pasos fronterizos ilegales que han sido controlados de manera estricta por hombres armados que son los encargados de recaudar el "peaje" o tributo económico para atravesar la frontera (Fundación Progresar, 2017; Fundación Paz y Reconciliación , 2021, pág. 8). En algunos casos, cuando los hombres migrantes no poseen la cuantía económica para cruzar son golpeados y devueltos, o reclutados para actividades económicas ilegales; para el caso de las mujeres, en algunas ocasiones su cuerpo se constituye como una "moneda de cambio" para que los traficantes abusen sexualmente y "recauden" el paso del grupo, en otras ocasiones son violadas de manera masiva (Banco Mundial , 2018, pág. 21; Pineda \&

2. Segato $(2013 ; 2016)$ señala que la violencia contra las mujeres en los espacios públicos de las fronteras tiene un componente político, pues la violencia sexual se ha corporalizado y es el cuerpo el lugar donde se hace política. La apropiación de lo concreto, es decir del cuerpo, en contravención de la posesión de la vida, puesto que esta resulta abstracta de posesión. En cambio, el cuerpo tangible, físico sobre el que se pueden trazar las relaciones de poder políticas y económicas es arrancado, física y simbólicamente en el mismo instante en el que la mujer no tiene decisión y autonomía sobre é cuando es sometido violentamente.

3. Rita Laura Segato trabaja sobre la idea de que en la actual etapa de globalización hay territorios fronterizos en la región latinoamericana donde la coerción, la ley y el orden social, económico y político no es ejercido por el Estado legal, sino que la instauración de estructuras de crimen y violencia organizada cuyas actividades económicas para su financiación son ilegales y constituidas por la relación de dominación masculina. Así tengan es su estructura mujeres cómplices de las estructuras paralelas al Estado, generan una cofradía de autoridad y gobierno a partir del control territorial por vía armada, pero también con la complicidad de algunas instituciones legales. El Segundo Estado, es el estado paralelo, mafioso, ilegal, cuya autoridad masculina patriarcal gobierna todo cuanto circule en el territorio. 
Ávila, 2019, pág. 82; Universo Centro, 2020).

Una forma de aproximarse a explicar estas prácticas violentas contra las mujeres, tiene que ver con que estas son asociadas principalmente con la sexualidad y, de manera adicional, las mujeres negras son identificadas con “... la sexualidad desenfrenada”, de allí que las características corporales de ser mujeres voluptuosas coincida con el estereotipo patriarcal de posesión del cuerpo femenino para la satisfacción del deseo masculino, es decir la sexualización de la raza y la etnia (Young, 2000, pág. 218) se configuran como elementos que pueden explicar estas acciones violentas.

De esta manera, la experiencia migratoria de las mujeres es distinta según su género, clase social y estatus migratorio. Pero, ¿de qué manera las mujeres migrantes han experimentado el proceso migratorio en relación con el carácter sexual de su cuerpo? Los aportes de Rita Laura Segato $(2013 ; 2014 ; 2016)$ a la teoría social, en diálogo con las contribuciones de otros autores orientan una aproximación a explicar al anterior interrogante, pero también es importante cuestionarse: ¿cómo existe un carácter político en la violación sexual de las migrantes en la frontera colombo-venezolana? Estas mujeres, cuyo estatus migratorio es de irregularidad en la ruta migrante, han experimentado la sujeción, el control de sus cuerpos y la violación sexual a manos de las estructuras paraestatales mafiosas y patriarcales, que sobre el entendimiento de la posesión de las mujeres como un bien común que les pertenece a todos (Guillaumin, 1978; 2005), ejercen una apropiación de los territorios y de los cuerpos que circulen en ellos.

Así, la violación sexual sobre estas migrantes tiene un componente sexual, pero además, los múltiples actores que profanan sexualmente a estas mujeres han producido las condiciones para la violación por oportunidad ${ }^{4}$, pues en un contexto de capitalismo global con estructuras paraestatales para el control territorial económico y político se produce un ecosistema patriarcal-mafioso, alimentado por la xenofobia y el racismo que coincide con la condición de irregularidad migratoria, de una clase social dominada y perteneciente a un grupo social no hegemónico patriarcal (Lugones, 2013), donde estas diferencias las ubican en una situación de doble o triple vulnerabilidad, y la violencia sexual ejercida sobre ellas es una expresión política del mandato masculino de poder de las corporaciones mafiosas.

\section{Marco teórico y aclaración conceptual}

Desde la mirada crítica al proceso migratorio internacional han surgido vertientes políticas e historiográficas generales; por un lado, la postura anticolonial, marxista y feminista advierte que el movimiento internacional de personas es una migración de fuerza de trabajo como un recurso explotable de mano de obra económica y no calificada e inactiva que el capitalismo e imperialismo global aprovecha para generar mayores ganancias a las corporaciones (Chalcraft, 2007). En esta línea, la migración más reciente a nivel global, incluida la migración de mujeres venezolanas hacia Colombia, está marcada por la migración pauperizada y de sobrevivencia, debido a que desde el origen, el tránsito y el destino cuentan con altos grados de desprotección social y económica, pues las migrantes, cuya situación jurídica migratoria es de irregularidad, buscan superar la pobreza, la injusticia social, el detrimento de sus condiciones de desarrollo humano y el desempleo (Sassen, 2006, pág. 21). Estas mujeres buscan llegar a los mercados laborales de explotación y flexibilización en entornos de discriminación masculina y étnica, con el fin de hallar seguridad y sobrevivencia en su nueva vida (Herrera, 2021).

Ahora, la violencia, tomando en cuenta la teoría sobre la justicia de Young (2000), se comprende como los actos, ejercicios y expresiones de degradación, humillación, estigmatización que se despliegan sobre los grupos sociales y sus miembros. Esta violencia es un ejercicio socialmente reconocido y aceptado que está presente en el imaginario colectivo de una sociedad, y que se asume como hegemónico, pues la violencia es ejercida sobre las comunidades cuya diferencia los ubica en una posición inferior. Young (2000) señala que esta violencia tiene un carácter sistemático. Para este caso, el hecho de ser mujer, pertenecer a una etnia no dominante, corresponder

4. La violencia por oportunidad se entiende en los episodios en los que las mujeres son abusadas sexualmente porque las circunstancias las dejaron en condicion de vulnerabilidad, y aunque el medio de la violencia de los perpetradores no fuera necesariamente el sexual, lo ejercen como un reflejo de grupos estatales y paraestatales o hechos de violencia aislados a un conflicto armado interestatal. 
a una clase social con pocas ventajas y tener un estatus migratorio irregular, la violencia física, verbal, simbólica, y para efectos de este artículo, la sexual es ejercida por el hecho de encarnar estas condiciones.

El fenómeno de violación sexual a las migrantes venezolanas se puede atribuir a factores como la asimetría jerárquica de género, que ubica lo masculino en una nivel dominante y superior sobre la mujer (Pineda \& Ávila, 2019); también, la discriminación por ser mujeres con un bajo capital social y económico, debido a las condiciones sociales que produjeron su éxodo desde Venezuela, y la vulnerabilidad y el temor por contar un estatus migratorio irregular ${ }^{5}$. La violación sexual a mujeres en contextos de migración, más que ser una característica de estas, representa una expresión de la constante desigualdad de sexos y la dominación del hombre sobre la mujer, pues existe la creencia de que la mujer es naturalmente débil y sumisa sexualmente, y los hombres son agresivos y con un alto apetito sexual. Esta dicotomía jerárquica alienta a pensar al hombre como sujeto dominante que usa y dispone de la mujer como objeto y sujeto complaciente pasivo del deseo sexual masculino (Peterson \& Sisson Runyan, 2013).

En este sentido, la violencia ejercida sobre las migrantes en las fronteras se puede entender desde los aportes de Mischkowski (2013) como una violencia sexualizada o sexual que está asociada a un tipo de dominación, poder y sumisión sobre el cuerpo de un sujeto, no con el propósito de satisfacer deseos sexuales, sino más bien por el objetivo de degradar y humillar de manera violenta a través de la intervención en el área íntima (Mischkowski, 2013). Por su parte, Kate Millet señala que el sistema patriarcal se reafirma en una dominación violenta sexual que se manifiesta en la violación o penetración sexual (Millett, 2000). Así mismo, Marcela Lagarde (2005) advierte que la violencia erótica es la manifestación más inteligible de la opresión sobre las mujeres, porque contempla la dimensión política de la violación como la apropiación y el daño sobre el cuerpo cautivo; y el aspecto psicosocial femenino, es la cosificación patriarcal sobre la mujer (Lagarde, 2005).

Por otra parte, las mujeres que han sufrido violencia sexual o sexualizada en el marco de la migración irregular han experimentado simultáneamente la invisibilización y objetualización de sus cuerpos, pues por sus condiciones sociales (mencionadas con anterioridad) producen y reafirman imaginarios sociales de que lo masculino puede ejercer posesión, dominación y apropiación sobre los cuerpos femeninos. De allí que Colette Guillaumin (1978; 2005) explique la existencia de una naturaleza específica de opresión sobre las mujeres relacionada con la apropiación de ellas, donde la mujer se convierte en pieza de intercambio y es tomada como simple unidad material, que en el marco de la relación de poder lo masculino se apropia físicamente del cuerpo de la mujer en diversas formas. Una de ellas en la apropiación de los productos del cuerpo expresado en la obligación sexual, asumido como un derecho del hombre a la penetración en contravención del cumplimiento de un deber por parte de la mujer; este uso y control físico y sexual toma forma en la violación (Guillaumin, 1978; 2005, pág 30).

\section{Metodologia}

El presente artículo tiene un carácter descriptivo y analítico. En este sentido, como lo señalaba Weber (1904), citado por Hernández-Sampieri (2018) \& Baynes (2017), "vestehen” (en alemán) o "entender" (en español), y el "interpretativismo", son importantes dentro de la investigación científica social, pues permite revisar los significados que las personas dan a sus acciones a través de la descripción y medición de las variable sociales con el fin de "comprender los significados subjetivos y contextos en los que ocurren los fenómenos (Hernández-Sampieri, 2018, pág, 4).

La ruta seguida para el desarrollo del artículo tuvo las siguientes etapas: primero, la planeación. En esta etapa se establecieron los interrogantes más importantes que dieron forma al diseño metodológico del manuscrito, como menciona Packer (2019), es la pregunta de investigación la que debe guiar la investigación científica y este diseño debe ajustarse a las exigencias de la pregunta.

La segunda fase de revisión de literatura académica y rastreo de archivo se llevó a cabo a partir de un muestreo por juicio. Se seleccionó el archivo documental para la revisión basado en la

5. El estatus de migración irregular hace referencia a la situación jurídica y política de ilegalidad; la no autorización, la indocumentación o no autorización de ingreso o asentamiento de una persona o grupo de personas que se desplazan de un Estado-nación de un origen a otro (Castles \& Miller, 2009). 
coincidencia de las variables teóricas y conceptuales que delimitan la composición estructural del artículo (Mejía, 2000). Así, entonces, la revisión bibliográfica y documental de literatura académica de la autora Rita Laura Segato, la exploración de fuentes secundarias de los informes de Migración Colombia, de la Fundación de Paz y Reconciliación, de la Fundación Ideas para la Paz y fuentes periodísticas como la revista Universo Centro, que, durante el año 2020 visibilizaron y dieron a conocer a la opinión pública los casos y episodios de violencia sexual o sexualizada sobre las migrantes venezolanas en la frontera binacional en la más reciente etapa de movilidad humana desde el vecino país, permitieron obtener la información cualitativa sujeta a interpretación.

Y la tercera y última etapa correspondió al análisis de la información. En esta se procedió a organizar y establecer categorías y etiquetas de análisis tales como "violencia sexual contra mujeres en contexto de migración”, "migración irregular y vulnerabilidades", "violencia de género en la frontera", "migración venezolana con enfoque de género", entre otras. Esta información fue codificada a partir del protocolo de codificación que se derivó del análisis conceptual y teórico, y la operacionalización de los conceptos más potentes de los aportes de Segato, para, finalmente, pasar al procesamiento de la información cualitativa por un software especializado, y proceder a la escritura del artículo.

En este sentido, el manuscrito tendrá un límite temporal, de universo poblacional y teórico del fenómeno social a observar. En primer lugar, se revisan los relatos que la revista Universo Centro publicó en junio de 2020 de la experiencia de aproximadamente 10 mujeres que experimentaron la violencia sexual o sexualizada que junto con otras migrantes sufrieron en la frontera binacional al cruzar de manera clandestina por las "trochas". Por lo anterior, se retoman de manera complementaria los archivos documentales de instituciones como la Fundación Paz y Reconciliación, la Fundación de Ideas para la Paz y la Fundación Progresar, que desde el 2017 hicieron públicos en sus informes sobre las líneas de trabajo de Migración, seguridad $\mathrm{y}$ fronteras, los casos de violencia sexual en la frontera. En la arista teórica, los aportes de Segato (2013; 2016) referentes a la violencia contra las mujeres en las fronteras como espacio para hacer política por parte del Segundo-Estado marcan el límite teórico del artículo.

En consecuencia, el objetivo general de este artículo es aproximarse a analizar la violación sexual que han experimentado las mujeres migrantes venezolanas en las zonas bifronterizas entre Colombia y Venezuela en el más reciente éxodo de habitantes venezolanos hacía Colombia, a partir de la reflexión sobre los aportes teóricos de Rita Laura Segato (2016) acerca de las nuevas expresiones de la violencia contra la mujer y de cómo en el cuerpo de estas se escribe un mensaje de control político por parte de las estructuras paraestatales mafiosas sobre un mandato masculino, con el fin de demostrar que la violación sexual sobre las migrantes venezolanas tiene que ver más con una expresión de poder político que con el deseo sexual.

$\mathrm{El}$ artículo está dividido en tres partes, la primera es la introducción en la cual se propone la problemática y preguntas subyacentes de la misma, y se presenta el horizonte teórico y conceptual que guiará la indagación; en la segunda parte, se abordarán dos interpretaciones sobre la violación sexual a las migrantes. Una tiene que ver con el componente de la sexualización del cuerpo femenino y la sujeción de este mediante la violación sexual, y la otra dará cuenta del carácter político de la violación sexual como expresión del control territorial de las estructuras mafiosas masculinas. En la tercera parte del artículo se brindarán los comentarios finales de la discusión.

\section{Dos aproximaciones a la violencia sexual contra las migrantes venezolanas en la frontera colombo-venezolana}

A continuación, se proponen dos aproximaciones interpretativas acerca de la violencia sexual contra las migrantes en los pasos clandestinos entre Colombia y Venezuela. Se entiende que existen diversos componentes que están inmersos en la violencia sexual sobre estas mujeres migrantes; sin embargo, a la autora de este documento le interesa trabajar sobre dos componentes en particular: lo sexual y lo político.

\subsection{El componente sexual en la violación a las migrantes}

La sexualización del cuerpo de la mujer está relacionada con los roles de género, que siguiendo a 
Butler (2002) tienen que ver con la norma cultural que conduce a la tangibilidad de lo corporal, pues la producción del género no es una imposición artificial en relación con el sexo, ni una construcción lingüística que asume al sexo como natural y prelingüístico y al género como una construcción discursiva de la articulación cultural. De hecho, la tensión entre sexo y género abordada por Beauvoir (1949; 2019) ha sido ampliamente criticada, pues asumir que lo natural (el sexo) necesita del reconocimiento y significación social para adquirir valor implicaba asumir que lo natural -el cuerpo sexuado- requería ser una superficie para la inscripción social y lograr así el reconocimiento (Butler, 2002, pág. 22), de tal suerte que el género solo existiría en la medida en que las operaciones lingüísticas culturales, sociales y políticas dieran forma corporal a un sujeto sexual natural.

En este sentido, el género tiene que ver con las normas de las fuerzas reguladoras del sexo para la performatividad y tangibilidad del cuerpo en un esfuerzo de materializar el sexo y producir la diferencia heterosexual del binario hombre-mujer. Luego, el poder constituye el principio estático del cuerpo a través del género, que citando a Foucault (1976) implica advertir que las prácticas sociales de exclusión y las tecnologías del poder avanzan para recluir el yo sexual (Foucault, 1976; 2019). En la normatividad del cuerpo que ya no puede entenderse de manera independiente a la materialidad de la norma reguladora Butler (2002) señala que el sexo será una de las regulaciones a través de las cuales alguien pueda llegar a ser viable y la calificación de su cuerpo le dará la aceptación cultural (Butler, 2002, pág. 19). El género puede entenderse como una práctica de identificación persistente en los sujetos a través de la materialización normativa y regulatoria del sexo.

En esta línea, al revisar la dominación física y la violencia sexual que han experimentado las migrantes en la zonas fronterizas colombovenezolanas en el quinquenio más reciente, se señala que en este contexto las migrantes son vistas como seres sexuales, no para ellas mismas, sino al servicio y disponibilidad de los varones, pues las normas reguladoras del género les han asignado un rol que históricamente ha estado vinculado con el placer, la sensorialidad, la complacencia sexual, la atención de los deseos y necesidades del cuerpo (Young, 2000). Además, la apropiación física de la que son sujetas las mujeres en la violación sexual puede ser vista como una posesión derivada de la obligación sexual que tienen las mujeres por ser consideradas bienes públicos, cuyo uso, entre otros, es el físico-sexual (Guillaumin, 1978; 2005).

El caso de la sujeción de sus cuerpos y la violencia sexual experimentada por las migrantes venezolanas está arraigado con el imaginario colectivo de asociar esta violencia al ámbito privado y doméstico, pues el campo de los deseos, de lo sensorial, de lo sexual femenino, no debe ser un asunto de discusión pública, ya que es un fenómeno que solo afecta a un grupo social, aparentemente minoritario, y cuyo estatus social es el de ser un grupo dominado, por su género, su clase social y, en este caso, por su estatus migratorio. Estas violaciones han contado con condiciones habilitadoras asociadas con la subvaloración de las mujeres y la reducción de sus experiencias sociales al espacio privado-doméstico, pues la narrativa hegemónica asocia los asuntos de las mujeres con la privacidad.

No obstante, desde el feminismo de los años 60 se abogó por sacar del espacio privado la violencia contra la mujer y llevarla a la esfera pública a partir del eslogan "lo personal es político", pues si bien la violencia sexual o sexualizada -en este caso- sobre las migrantes se ejerce por grupos paraestatales, no se puede desconocer que estos episodios pueden ser representaciones de los fenómenos de politización pública que impactan a más de un grupo de 10 migrantes venezolanas que decidieron hacer visible una situación de vulnerabilidad.

En concordancia, Segato (2018) retoma su investigación acerca de los crímenes sobre las mujeres en la frontera norte de México y resalta el caso paradigmático de Ciudad Juárez para señalar que las violaciones sistemáticas y multitudinarias, los cuerpos arrojados al desierto, las desapariciones y la muerte de mujeres a causa del abuso sexual mezclado con violencia física de las migrantes y lugareñas en la frontera, no pueden ser visitos solamente como crímenes de género, que sí lo son, pero que no tienen las mismas características a los feminicidios que tienen lugar en el espacio doméstico y que están asociados con las relaciones intimas (Segato R. , 2018).

En consecuencia, la autora defiende la idea de que existen una serie de fenómenos violentos que suceden en los espacios públicos, y que las mujeres 
son violentadas y asesinadas solo por el hecho de ser mujeres. A esos crímenes, Segato $(2016 ; 2018)$ los define como "femigenocidios", concepto que comprende una diversidad de crímenes cometidos contra mujeres y que están relacionados con las formas de accionar paraestatales que se manifiestan en ejercicios de "violencia y control de poblaciones, desde el conflicto interno, el terrorismo de Estado, duplicación del Estado en formas estatales y paraestatales ... también el avance de corporaciones armadas tipo mafioso" (Segato R. , 2018, pág. 73). En esta línea, las migrantes violadas y asesinadas no tienen que verse simplemente como efectos colaterales de la migración irregular a nivel global, ni como el resultado del enfrentamiento entre los grupos al margen de la ley que operan y controlan la frontera colombo-venezolana, este fenómeno puede verse como la misiva enviada a la sociedad del poder paraestatal que tienen sobre los territorios los recursos y sus comunidades los grupos paraestatales mafiosos.

... Hay un mundo en el que las mujeres tienen que elegir entre dejarse violar por siete hombres o desaparecer. No es una metáfora. Hablo de desaparición forzada.

-Te dicen, pue, que ya sabes lo que te toca. Dicen: "Si usted colabora, usted se devuelve o para Colombia o para Venezuela, para donde usted quiera, pero si usted no colabora, usted no vuelve a aparecer más”.

— ¿Te dijeron eso?

—Sí. (Universo Centro, 2020, párr. 08).

... Las trochas más peligrosas quedan en dos sectores: las que conectan a San Antonio del Táchira con La Parada, sector de Villa del Rosario, municipio del área metropolitana de Cúcuta; y las que conectan al municipio venezolano de Ureña directamente con un barrio cucuteño llamado El Escobal. (Universo Centro, 2020, párr. 09).

Todas dicen que es más peligroso este último, por eso prefieren entrar a Colombia por San Antonio. En una de las trochas de Ureña, siete hombres violaron a Gabriela.

-No te hacen todas las cochinadas de una. Ellos esperan a que pasen varias mujeres y van acumulando unas, y te dejan ahí, te dicen que esperes ahí. Y ya en la tarde, unos hombres caratapada vienen con unos cuchillos y te llevan. Lo meten a uno bien adentro de la trocha, como en el monte. $Y$ ahí es donde le dicen a uno que, si uno no colabora, no vuelve a aparecer.
Verónica también mencionó a los "caratapada", dijo que el día que estaban violando a la mujer que gritaba auxilio, ella los vio. (Universo Centro, 2020, párr. 33).

Estos relatos de algunas migrantes violadas permiten revisar cómo la violencia sexual contra ellas en la frontera binacional tiene como uno de sus componentes el género y la sexualización del cuerpo femenino, pues este proceso fue trazado en la modernidad occidental donde se conceptualizó de acuerdo con las normas reguladoras del género que las mujeres tienen marcadamente la naturaleza sexual y su aprendizaje corporal está asociado a la reproducción y la seducción (Esteban, 2004). Además, es importante revisar que las crónicas de estas mujeres dejan ver cómo las trochas son el escenario para el sometimiento de sus cuerpos, y de allí que no se puede desconocer que el estatus migratorio de irregularidad crea la oportunidad para que las mafias paraestatales en la frontera colombo-venezolana creen y controlen los pasos fronterizos ilegales.

En estas zonas de difusa distinción entre lo político y lo económico, lo legal y lo ilegal, lo legitimo y lo ilegitimo, lo local y lo global, además de las disputas en la frontera, queda de manifiesto que el control de los cuerpos políticos y la producción de terror se constituye como un mecanismo de exhibición de su autoridad masculina. La violencia física sobre los hombres migrantes es una expresión de su masculinidad frente a sus pares, pero sobre las mujeres migrantes el ejercicio de violencia no consiste más que en suspender su vida y dar muerte a ellas, que en controlar la vida misma, en someter la condición humana a la indignación, en tomar su cuerpo como espacio para escribir la política criminal y el poder masculino. Es el cuerpo de las migrantes desposeídas de ellas mismas, pero apropiados y poseídos por sus profanadores el que es usado para estampar la impronta del poder de los grupos de crimen organizado cuyas actividades económicas ilegales, entre ellas el tráfico de migrantes, trata de personas, explotación sexual, alimentan un sistema capitalista global cuya autoridad y estructura está atravesada por las relaciones de poder y su distribución desigual con relación al género, al sexo, la etnia, la clase social y en este caso, por el estatus jurídico de irregularidad, que ha sido resultado de una operación estatal del régimen migratorio colombiano. 
Desde esta óptica, la sujeción de los cuerpos de las migrantes como objetos de placer está contemplada en las normas reguladoras de la feminidad donde la sexualidad es concebida como un atributo natural y un eje de identidad de las mujeres, que a través de representaciones simbólicas, de los discursos, reafirman el imaginario colectivo de la "normalidad femenina", lo que significa aceptar la inferioridad jerárquica de género, puesto que las estructuras simbólicas patriarcales asumen como estático y monolítico el proceso de sexualización del cuerpo femenino para el placer masculino y reducen a las mujeres a la disposición política de ellas para ser accedidas sexualmente con o sin su voluntad.

Existe la creencia de que estos cuerpos están disponibles para ser poseídos y controlados, pues esta sujeción tiene lugar en la relación de dualidad que se expresa en el espíritu del enfrentamiento de un grupo de hombres contra otro grupo de hombres donde las mujeres constituyen una parte de las propiedades que para los hombres representan un instrumento de intercambio (Beauvoir S. d., 1949; 2015). De allí que las bandas criminales ilegales en la frontera binacional a modo de transacción económica soliciten como moneda de cambio a una mujer o a varias del grupo de migrantes irregulares para cruzar la frontera.

De manera adicional, la violación a las migrantes se circunscribe en los múltiples tipos de violencia sexual dentro de los cuales se encuentran: la tortura sexual, la violación sexual, la violación como estrategia y la violación por oportunidad (Enloe, 1983; 2000). En este sentido, el cuerpo de la mujer y la violencia ejercida sobre ella -aunque no exclusivamente- generalmente en la literatura académica y en los hechos materiales es abordada en circunstancias de guerra y conflictos formales entre grupos beligerantes. No obstante, como ha señalado Segato (2016), la violencia sexual en manifestación de la violación ha sido un mecanismo de representación de poder, ya no solamente por parte de los ejércitos nacionales regulares, sino que en la actual conflictividad de la época globalizada los ejércitos paraestatales han adoptado esta práctica como una representación de su control y poder territorial de las corporaciones mafiosas
(Segato R. L., 2016). De esta forma, en la frontera colombo-venezolana la presencia de grupos de crimen organizados transnacional, en ocasiones con complicidad de las autoridades legales de ambos países, profanan los cuerpos de las migrantes que cruzan por los caminos clandestinos. Esta violencia que no es ejercida azarosamente por un individuo y de manera privada sobre su víctima, podría ser entendida como una violencia colectiva.

Esta categoría, la de violencia colectiva, ha sido trabajada por Charles Tilly (2003) para dar cuenta sobre la violencia masiva de carácter político ejercida por los regímenes estatales sobre la población, con el fin de generar dominación sobre los desposeídos de poder, de tal suerte que esta violencia no solo produce un castigo sino un mecanismo de disciplina para la conformación de un orden social (Tilly, 2003). En este sentido, se propone explicar la violencia sexual contra las migrantes como un tipo de violencia colectiva, ya no ejercida por agentes estatales sino de un Segundo Estado -un régimen paraestatal-, cuya violencia es sexualizada pero tiene un carácter político. En algunas ocasiones, estas violaciones pueden ser una estrategia del grupo armado ilegal con el fin de demostrar a los habitantes y a otros grupos presentes el control sobre el territorio, pero también son violaciones por oportunidad (Wood, 2008).

Estas se presentan cuando los grupos que ejercen la violencia han creado los escenarios para apropiarse no solo del territorio o los bienes, sino de las personas que habitan o circulan en él; es decir, la oportunidad no debe ser vista como un evento al azar en el que la mujer se encuentra en un contexto y condiciones particulares para ser violentada ${ }^{6}$, sino por el contrario, como un escenario creado por el perpetrador donde a través de la violencia física, la amenaza armada, el control del territorio, el saqueo, la posesión y la ausencia estatal, la mujer queda a disposición para que los grupos ilegales se apropien de sus bienes económicos y de sus cuerpos, y la oportunidad de violar, también es una oportunidad de matar y saquear (Wood, 2008). En consecuencia, la ausencia de un código que sancione o castigue ese tipo de violencia al interior del grupo perpetrador, la posición jerárquica del profanador, el liderazgo del grupo armado en el territorio, se convierten en

6. Se aclara que no se pretende señalar que existen violaciones porque las mujeres han dado la oportunidad, pues no se defiende la idea de que la mujer provoca y brinda las condiciones de ser apropiada y profanada sexualmente, por el contrario, este apartado argumenta que quien crea la oportunidad
es el perpetrador, de tal suerte que la mujer no tiene posibilidad de eludir la violencia. Es decir, la oportunidad la crea el perpetrador, no la victima- 
unidades de análisis para evaluar de qué forma las violaciones tienen un carácter político a través de la sexualización de sus cuerpos (Wood, 2008), pues las mujeres en estos contextos donde convergen elementos de control paraestatal del territorio, uso irregular de la fuerza física y bélica, actividades económicas ilegales y la presencia de mujeres en situación de vulnerabilidad por condiciones como su género, etnia, lugar de origen, clase social, y en este caso, su estatus migratorio, las ubica en una posición desfavorable para que infrinjan sobre ellas violencia sexual que es de carácter público y no doméstico.

\section{2 "Lo personal es politico": la violencia sexual contra las migrantes en la frontera es politica.}

El primer aspecto a tener en cuenta es que las violaciones ejercidas sobre las migrantes en la frontera están principalmente relacionadas con prácticas violentas a cargo de grupos al margen de la ley que se disputan el control territorial de las zonas y las rutas en las cuales operan y transitan las actividades de las economías subterráneas ${ }^{7}$ (Sassen, 1999; 2003), aunque como lo propone Mary Kaldor (2011), en la actualidad existe una difusa línea divisoria entre lo estatal y paraestatal. De tal manera que, las bandas criminales ilegales que operan en la frontera cuentan con la complicidad de funcionarios de las instituciones estatales de Colombia y Venezuela (Fundación Ideas para la Paz, 2018, pág.13; Fundación Paz y Reconciliación, 2019), así que la ficcionalidad y duplicidad del Estado es una característica de este fenómeno.

Así, las violaciones que se cometen sobre las migrantes venezolanas en zona de frontera pueden ser vistas como crímenes de Estado, pero no del Estado legal y legítimo jurídicamente, sino del Segundo Estado, entendido como un Estado paralelo corporativista de organizaciones y redes de crimen organizado transnacional, quienes a través de la violencia sexual patriarcal sobre las mujeres expresan su poder político de control del territorio y lo que este contenga o circule por él. En este sentido, la expresión de este poder político a través de la violencia sexual sobre mujeres con características particulares no está relacionado necesariamente con la acumulación capitalista, sino con elementos de carácter simbólico. Su poder político produce la otredad, la posesión de lo diferente, de la mujer migrante mestiza, de la extranjera clandestina, de esta forma, la acumulación capitalista es un elemento sustancial que consolida la jerarquía de los perpetradores sobre la pobreza de las migrantes y las comunidades limitrofes entre ambos países (Segato R. L., 2016, pág. 51).

La violación a las migrantes expresa la capacidad de dominación, supresión y opresión sobre el otro, pues resulta una expresión simbólica del poder territorial, social, económico y político, por tanto “...es emblemático el sometimiento del cuerpo de la mujer mestiza, de la mujer pobre, de la hija, hermana, madre de otros que son pobres y mestizos" (Segato R. L., 2016, pág. 51). En consecuencia, la violación, el consumo del cuerpo, el odio hacia el cuerpo de la mujer extranjera hace parte de la construcción de un sistema de poder patriarcal paraestatal donde la violación tiene que ver más con el deseo de expresar el poder político por medio de un cuerpo-territorio que con el deseo sexual (Segato R. , 2018).

En esta línea, Segato (2018) propone que actualmente ha emergido una nueva clase de violencia contra la mujer, donde el cuerpo de esta ha adquirido un significado renovado adjudicado a través de las masivas violaciones, ejercidas por actores irregulares, de difícil distinción, borrosos ante la ley y la sociedad; es decir, en los conflictos armados y bélicos anteriores a la Guerra Fría, la violencia sexual contra la mujer tenía un actor reconocido y visible: los ejércitos nacionales o ejércitos regulares. En cambio, en la actualidad, y como lo señala Kaldor (2001), en las nuevas guerras, los nuevos actores armados ilegales son los perpetradores de la violencia. Esta mirada de Kaldor se ajusta con la explicación de Segato (2018) sobre la violencia contemporánea en las fronteras ejercida por la expansión paraestatal que tiene como objetivo el control de los territorios y de la vida en su parámetro de influencia (Kaldor, 2001; Segato, 2018, pág.70).

7. Saskia Sassen ha planteado que los circuitos económicos globales están constituidos por los legales e ilegales, los legales están relacionados con las actividades económicas contempladas en la OMC, y las ilegales están contempladas con actividades relaciones con el crimen organizado

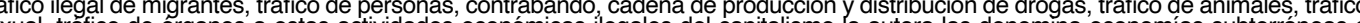
sumergidas
suxplotalico de organos a estas actividades economicas ilegales del capitalismo la autora las denomina economias subterraneas o 
En este sentido, es importante mencionar que en las zonas de frontera binacional a lo largo de sus 2.200 kilómetros existe una fuerte presencia de grupos al margen de la ley que controlan el territorio; es decir, se manifiesta el concepto de Segundo Estado que trabaja Segato. En particular, en la frontera de Norte de Santander se cuenta con presencia del ELN, EPL y, en menor medida, de Los Rastrojos; existe una disputa por los territorios y el control de las economías criminales. Además, la precaria capacidad del Estado respecto a los flujos migratorios procedentes de Venezuela ha generado un escenario favorable para que los grupos ilegales se apropien de las "trochas" y los flujos que transitan en ellas (Fundación Ideas para la Paz, 2018, pág.13). Por eso, la violación a las migrantes venezolanas manifestó la destrucción de lo corporal y la ocupación depredadora, no solo de un territorio, sino de todo cuanto tenga vida allí a manos del predominio de la informalidad, por ello la violencia contra la mujer contiene un carácter político, a pesar de que los intereses del Segundo Estado sean difusos entre lo político y lo económico, y la amalgama de las dimensiones de la territorialidad, la política, la economía y el patriarcado configuran un sistema de poder paraestatal donde el cuerpo femenino o feminizado pasa de tener un lugar marginal a uno central (Segato R. L., 2013).

Desde este ángulo, en estos casos la violación puede separarse del deseo y el placer sexual, pues el componente de sexualización del cuerpo está presente en la profanación, pero no es el principal factor para estos crímenes, y cuando es el motivo primordial, este ya está contemplado en el pacto corporativo masculino-mafioso. Además, la condición de ser mujeres y ser migrantes irregulares las ubica como cuerpos dispuestos a la posesión y apropiación de la alianza patriarcal-mafiosa -también en estas estructuras mafiosas hay mujeres, pero su complicidad frente a la violencia ejercida sobre las migrantes las hace parte del pacto entre hombres- (Kaldor, 2001; Sassen, 2003; Segato R. L., 2014). Así, la estimulación de violencia sexual está más en el orden de la reducción moral y subsunción de la capacidad política de la mujer, que en la satisfacción sexual del profanador. La violación sobre estas mujeres no solo implica el uso y abuso de sus cuerpos, sino la reducción de la víctima y la desposesión de sí misma. Es la pérdida de la soberanía del territorio de su cuerpo y de sus subjetividades (Segato R. L., 2016).
Es cierto que el mecanismo para esta violencia es la sujeción sexual, pero lo que logra el perpetrador es la devastación moral de la mujer y de la sociedad a la que representa. Este efecto es alcanzado porque existe la antigua creencia arraigada a la sociedad de que una mujer no es dueña de sí misma, sino que le pertenece a otros (Guillaumin, 1978; 2005). Además, ella debe estar bajo la custodia de un tutor, y en caso de que esta sea profanada sexualmente, será su cuerpo la superficie donde se escriba el mensaje de humillación para su tutor, su familia y su esfera social (Segato R. , 2018). A su turno, Millett (2000) señala que el patriarcado, como sistema de poder, está basado en la dominación, apropiación y posesión sobre lo femenino, y uno de los mecanismos para el ejercicio del poder es la violencia sexual que se consolida en el acto de violación, que ha sido entendida clásicamente como una ofensa al varón cuidador y tutor. La mujer es vista como la víctimaobjeto sacrificial, pues a través de ella se profana el territorio masculino contrario, la agresividad sexual a la mujer es la expresión del desprecio y destrucción de la sociedad de origen de ella, es la manifestación del poder político por medio de lo sexual (Millett, 2000).

La mujer como sujeto sobre el que se impone el poder de masculinidad, representado en la virilidad del profanador, se convierte en objeto porque la profanación sexual a su cuerpo es un acto violento al tutor cuidador que debe velar moralmente por la mujer y proteger el cuerpo femenino, símbolo de la fecundidad y propiedad privada del tutor y su comunidad. Por eso, el pacto de masculinidad contiene el código de transaccionalidad entre el profanador y el tutor -pueden ser estructuras patriarcales-, donde la agresión sexual se traduce en agresión moral, y la mujer es el objeto sobre el cual se expresa el respeto o degradación al tutor y a la comunidad a la que pertenece (Segato R., 2016; 2018). De esta forma, es el mandato masculino sobre el cual se escribe el control territorial en el cuerpo de la mujer, el que puede tener la capacidad de torturar, matar y desaparecer; pues el espectáculo del poder sobre la vida en los territorios apropiados por los agentes paraestatales dejan de manifiesto que la institucionalidad legal y legítima del Estado es una ficción y el control de los cuerpos femeninos es la materialización de una institucionalidad clandestina con un mandato masculino e incorporada en los circuitos del capitalismo global. 


\section{A modo de conclusión}

Los aportes teóricos de Segato resultaron potentes para entender este indeseable fenómeno que aún sigue persistente en los procesos de movilidad humana entre Venezuela y Colombia, pues el cuerpo de la mujer y la política que sobre él ejercen los estructuras masculinas paraestatales ha manifestado que la violencia contemporánea no está más interesada en la necropolítica, sino en la biopolítica y en la selección sistemática de los cuerpos que no importan, de los cuerpos prescindibles femeninos racializados, empobrecidos y sin existencia jurídica, debido a su estatus migratorio, para escribir sobre ellos a través de la violencia sexual y sexualizada la autoridad masculina mafiosa que impera en los territorios entre Colombia y Venezuela.

Los rasgos de las actuales experiencias de movilidad humana en las Américas coinciden con el perfil migratorio de estas mujeres que, tras un éxodo por sobrevivencia y dejando en origen a sus familias, desafian y luchan en la ruta migratoria por arribar a Colombia con la expectativa de retornar remesas ${ }^{8}$ a sus familiares venezolanos. Pero estas mujeres, al igual que las de Ciudad Juárez, han sido desposeídas de sus cuerpos por el hecho de ser mujeres, mestizas, pobres, migrantes y por desafiar al mandato masculino que las obliga a cruzar la frontera con el hombre protector. Muchas veces en ausencia de él, son vistas por los perpetradores como las desprotegidas que deben asumir la responsabilidad de haber abandonado la tutoría masculina. Son estas migrantes en cuyos cuerpos se ha escrito el poder mafioso de los Pelusos, los Evander, los Rastrojos y otros grupos de crimen organizado transnacional que controlan la frontera, los que visibilizan cómo las relaciones de poder en los flujos de un mundo en globalización están atravesadas por el entrecruzamiento de las condiciones sociales de etnia, clase social y género. El mensaje de poder político manifiesto en la posesión del territorio, del cuerpo femenino a través de la violencia sexual es una expresión del capitalismo depredador que objetualiza y mercantiliza la vida.

Hemos de creer en la capacidad insurgente de las migrantes, en su poder de rebeldía e insurrección, en su fuerza de lucha y resistencia migrante para subjetivarse, para repolitizar y reapropiarse de sus cuerpos, haciendo de ellos un lugar de lucha, el mismo cuerpo que fue profanado, pero donde se podrá escribir el mensaje de las mujeres migrantes diversas que sin arraigo y sin nacimiento jurídico pueden ser sujetos políticos de las luchas migrantes.

\section{Referencias}

Álvarez, S. (2021). Tánsitos irregularizados. En I. Ceja, S. Álvarez , \& U. Berg, Migración (pág. 165). Cudad Autónoma de Buenos Aires: CLACSO.

Banco Mundial (2018). Migración desde Venezuela a Colombia: impactos y estrategia de respuesta en el corto y mediano plazo. Washington D.C: Banco Mundial.

Beauvoir, S. D. (1949; 2019). El segundo sexo. Francia; Madrid: Penguin Random House.

Butler, J. (2002). Cuerpos que importan sobre los limites materiales y discursivos del sexo. Buenos Aires \& Barcelona: Paidós.

Castles, S., \& Miller, M. (2009). The age of migration International Population Movements in the Modern World. London: Red Global Press.

Centro de Justicia y Paz. (2019). Incremento de casos de violencia secual y de género, enmarcado en la actual situación migratoria del país. Carácas: CEPAZ.

Chalcraft, J. (2007). Fuerzas de trabajo en Oriente Próximo. New Left Review, 45 (1), 26 - 47.

Enloe, C. (1983). Does khaki become you? The Militarization of Women's Lives. Berkeley y Los Ángeles: University of California Press.

Enloe, C. (2000). The international poitics of militarizing women's lives. Berkeley y Los Ángeles: University of California Press. https://doi. org/10.1525/9780520923744

Esteban, M. L. (2004). Antropología del cuerpo: género, itinerarios corporales, identidad y cambio. Barcelona: Bellaterra.

Foucault, M. ( 2019). La historia de la sexualidad I voluntad del saber. Madrid: Siglo XXI.

Fundación PARES. (2021). La trata de personas en la frontera colombo-venezolana. Bogotá: PARES.

Fundación Ideas para la Paz. (2018). Inseguridad, violencia y economías ilegales en las fronteras, los desafios del nuevo gobierno. Bogotá, Colombia: Fundación Ideas para la Paz.

Fundación Paz y Reconciliación. (2019). Sin dios ni ley: un análisis de la situación de la seguridad en la frontera colombo-venezolana. Bogotá: Fundación Paz y Reconciliación. 
Fundación Paz y Reconciliación. (2020). Seguridad y Migración en la frontera Colombia-Venezuela. Bogotá: Fundación Paz y Reconciliación.

Fundación Paz y Reconciliación. (2021). El viacrucis de las trochas: La Guajira y El Zulia, Norte de Santander y Táchira. Bogotá: Fundación Paz y Reconciliación.

Fundación Progresar. (2017). Una mirada local al crimen organizado en la frontera colombo venezolana. Bogotá: Fundación Progresar.

Guillaumin, C. (2005). Práctica del poder e idea de naturaleza. En Curiel, O., \& Falquet, J. (Compiladores), El patriarcado al desnudo. Tres feministas materialistas (p. 175). Buenos Aires: Brecha Lésbica.

Hernández-Sampieri, R., Collado, C., \& Baptista. M. (2014). Metodología de la Investigación (6 $6^{\mathrm{a}}$ ed.). México D.F.: McGraw-Hill/Interamericana Editores, S.A. DE C.V.

Herrera, G. (2021). Subjetividades. En I. Ceja, S. Álvarez , \& U. Berg, Migración (pág. 165). Cudad Autónoma de Buenos Aires: CLACSO.

Human Rights Watch. (2019). La emergencia humanitaria en Venezuela. Se requiere una respuesta a gran escala de la ONU para abordar la crisis de salud y alimentaria. Washington, D.C.: Human Rights Watch.

Kaldor, M. (2001). Las nuevas guerras. Barcelona: Tusquets Editores.

Lagarde, M. (2005). Los cautiverios de las mujeres: madresposas, monjas, putas, presas y locas. Ciudad de México: UNAM.

Lugones, M. (2013). Subjetividad esclava, colonialidad de género, marginalidad y opresiones múltiples. Guadalajara: Librería de Cuerpos Parlantes.

Migración Colombia. (2020). Radiografia venezolanos en Colombia. Bogotá: Migración Colombia.

Millett, K. (2000). Sexual Politics. Chicago: University of Illinois.

Mischkowski, G. (4- 5 de julio de 2013). "The Trouble with Rape Trials - The Prosecution of Sexual Violence in Armed Conflict from the Perspectives of Female Witnesses". "The Trouble with Rape Trials - The Prosecution of Sexual Violence in Armed Conflict from the Perspectives of Female Witnesses". Heidelberg, Alemania: Medica mondiale.

Navarrete, J. M. (2000). El muestreo en la investigación cualitativa. Investigaciones Sociales, 4 (5), 165 - 180. https://doi.org/10.15381/is.v4i5.6851

Packer, M. (2019). La ciencia de la investigación cualitativa. Bogotá D.C: Ediciones Uniandes. https://doi. org/10.30778/2018.47

Peterson, S., \& Sisson Runyan, A. (2013). Global Gender Issues in the New Millennium. Boulder: Westview Press.
Pineda, E., \& Ávila, K. (2019). Aproximaciones a la migración Colombo-venezolana desigualdad, prejuicio y vulnerabilidad. Misión Jurídica: Revista de derecho y ciencias sociales, 12(16), 59-78. https://doi.org/10.25058/1794600X.988

Sassen, S. (1999). La ciudad global. Buenos Aires: Universidad de Buenos Aires.

Sassen, S. (2003). Contrageografias de la globalización. Género y Ciudadanía en los circuitos transfronterizos. Madrid: Traficantes de Sueños.

Sassen, S. (2006). La formación de las migraciones internacionales: implicaciones politicas. Revista Internacional de Filosofía Política, 27(1), 19 - 40.

Segato, R. (2018). Contra-pedagogías de la crueldad. Buenos Aires: Prometeo.

Segato, R. L. (2013). Las nuevas formas de la guerra y el cuerpo de las mujeres. Ciudad de México: Tinta Limón. https://doi.org/10.1590/S0102$\underline{69922014000200003}$

Segato, R. L. (2014). El sexo y la norma: frente estatal, patriarcado, desposesión, colonialidad. Revista Estudios Feministas, 22, (2), 593-616. https:// doi.org/10.1590/S0104-026X2014000200012

Segato, R. L. (2016). La guerra contra las mujeres. Madrid: Traficantes de Sueños.

Tilly, C. (2003). The poitics of collective violence. Cambridge: University Press. https://doi.org/10.1017/ CBO9780511819131

Universo Centro. (2020 de julio de 2020). La trocha. Obtenido de La trocha: https://www.universocentro. com/NUMERO116/La-trocha.aspx

Wood, E. J. (2008). Sexual violence during war: toward an understanding of variation. En S. Kalyvas, I. Shapiro, \& T. Masoud, Order, conflict and violence, p. 450. Cambridge: Cambridge University Press.

Young, I. M. (2000). La justicia y la politica de la diferencia. Madrid: Ediciones Cátedra (Grupo Anaya, S. A.). 